\title{
Conservação pós-colheita de tomate-cereja orgânico embalados com filme ativo biodegradável à base de amido e óleo essencial de cravo-da- Índia
}

\section{Post-harvest conservation of organic cherry tomatoes packed with biodegradable active film based on starch and clove essential oil}

\author{
Mérida Layara Xavier Costa ${ }^{1}$, Aureluci Alves de Aquino ${ }^{2 *}$, Vivianne Cambuí Figueiredo \\ Rocha $^{2}$, Tania Aparecida Pinto de Castro Ferreira ${ }^{3}$, Edinilda de Souza Moreira ${ }^{3}$, Carlito José de \\ Barros Filho $^{2}$, Milton Ricardo Silveira Brandão ${ }^{2}$, Alencastre Honório Moura ${ }^{2}$
}

\begin{abstract}
RESUMO
As perdas pós-colheita de frutas e hortaliças, dentre elas o tomate cereja, promovem a elevação do custo e diminuem a qualidade e oferta dos produtos ao consumidor. A adição de filmes comestíveis pode diminuir a velocidade das transformações bioquímicas e fisiológicas que ocorrem no armazenamento devido ao seu amadurecimento. Este trabalho teve como objetivo desenvolver e aplicar filme ativo biodegradável à base de amido, amido modificado, gelatina e quatro diferentes concentrações de óleo essencial de cravo-da-Índia e verificar parâmetros físico-químicos dos frutos, como perda de massa, $\mathrm{pH}$, acidez total e ${ }^{\circ}$ Brix. Além disso, verificar a eficácia da adição dos filmes na vida útil dos frutos armazenados em temperatura ambiente, por até 12 dias. Os dados foram analisados segundo ANOVA e teste de Tukey. A adição de filme biodegradável com óleo essencial de cravo-da-Índia mostrou-se eficiente em prolongar o tempo de senescência dos frutos e no controle do crescimento dos microrganismos pesquisados. $\mathrm{O}$ filme ativo foi eficaz para a conservação dos tomates-cereja orgânicos, promovendo um aumento da vida útil do fruto.
\end{abstract}

Palavras-chave: Solanum lycopersicum; Vida útil; Novas tecnologias; Pós-colheita.

\begin{abstract}
Post-harvest losses of fruits and vegetables increase the cost of products and reduce the supply to the consumer. Its main causes are inadequate harvesting, transport and storage. Cherry tomato, for example, undergoes several biochemical and physiological transformations during ripening, significantly reducing its post-harvest life. In this perspective, this work aims to develop and apply a biodegradable active film based on starch added with clove essential oil, in the post-harvest conservation of organic cherry tomatoes. In addition, to evaluate its effectiveness when stored at room temperature environment. Initially, the shelf life of organic cherry tomatoes without packaging was verified. After this time, films containing in their composition starch, modified starch, gelatin and glycerol and different percentages of clove essential oil were manufactured, in order to evaluate the microbiological quality of organic cherry tomatoes. The active film was effective for the conservation of organic cherry tomatoes, promoting an increase in the shelf life of the fruit.
\end{abstract}

\footnotetext{
${ }^{1}$ Universidade Estadual de Montes Claros - UNIMONTES

${ }^{2}$ Instituto Federal de Educação, Ciência e Tecnologia Baiano

*E-mail: aureluci.aquino@ifbaiano.edu.br

${ }^{3}$ Universidade Federal de Goiás
} 
Keywords: Solanum lycopersicum; Lifespan; New technologies; Post-harvest

\section{INTRODUÇÃO}

O tomate (Lycopersicum esculentum) é considerado uma das hortaliças mais consumidas no mundo, tanto in natura quanto na forma industrializada. O Brasil está entre os 10 maiores produtores mundiais. Segundo o levantamento Sistemático da Produção Agropecuária e do Instituto Brasileiro de Geografia e Estatística (IBGE), em novembro de 2021, o país produziu 4.000.124 toneladas de tomate. É líder de produção na América Latina, representando 58,8\% da produção e possui uma das produtividades mais elevadas do mundo. O consumo da fruta contribui para uma alimentação saudável e equilibrada, pois são ricas em minerais, vitaminas, aminoácidos essenciais, açúcares e fibras alimentares (FAOSTAT, 2021; IBGE, 2021; CARVALHO; PAGLIUCA, 2007).

Existem vários tipos de tomate, dentre os quais se destaca o tipo cereja (Lycopersicum esculentum), que foi introduzido no Brasil na década de 1990. Destaca-se pela cor vermelha intensa ou amarela, ademais, possui alta firmeza, boa consistência, resistência a doenças e alto valor nutricional (JUNQUEIRA; PEETZ; ONODA, 2021).

A qualidade do tomate cereja depende de suas características físico-químicas, que influenciam na atratividade ao consumidor. Dentre os indicadores de qualidade sensoriais e nutricionais, estão a pectina total, pectina solúvel, relação sólidos solúveis/acidez, acidez titulável, vitamina $\mathrm{C}$ e açúcares redutores (ARRUDA et al., 2005).

A qualidade pós-colheita do tomate é muito importante, pois é um fruto altamente perecível após o apanhamento. O fruto maduro tem vida útil média de uma semana, com perdas que variam de $25,0 \%$ a 50,0\%. Já o fruto parcialmente maduro, apresenta vida útil de até duas semanas, com perdas pós-colheita de 20,0\% a 40,0\%. Inclusivamente, possui alto teor de água, estando sujeito a variações de temperatura e umidade relativa do ar, além dos danos mecânicos sofridos durante a produção, colheita, pós-colheita e comercialização, o que contribui para a redução da vida útil do fruto (CHIUMARELLI; FERREIRA, 2006).

Encontrar alternativas eficientes, não poluentes e de baixo custo para reduzir os danos pós-colheita do tomate cereja, sejam por perdas de qualidade ou por patógenos, é um desafio na sua cadeia produtiva. $\mathrm{O}$ uso de filmes comestíveis ativos feitos de polímeros naturais e biodegradáveis torna-se uma alternativa eficiente para prolongar a vida útil pós-colheita de frutas e hortaliças, principalmente como forma de reduzir a taxa de respiração, por meio do aumento do 
nível de $\mathrm{CO}_{2}$ e diminuição do $\mathrm{O}_{2}$, além disso, minimiza a perda de água e aumenta o valor agregado ao produto embalado (CISNERO-ZEVALLOS; KROCHTA, 2002; TURBIANI, 2007).

Um agente antimicrobiano utilizado no pós-colheita ideal deve ser eficaz em possuindo amplo espectro de ação e em baixas concentrações, não causar alterações nas características sensoriais do produto, ter custo compatível e atender à legislação vigente. Os óleos essenciais, que se caracterizam por serem misturas complexas de compostos orgânicos, são cada vez mais utilizados como antioxidantes e antimicrobianos. Ocupam um lugar preponderante nas indústrias farmacêuticas, agroalimentares, de perfumaria e cosmética, devido não só à possibilidade de obtenção de compostos aromáticos (odor e aroma agradáveis), mas também de compostos com propriedades terapêuticas e de proteção contra processos de oxidação e deterioração por microrganismos (BAKKALI et al., 2008; CHIUMARELLI; FERREIRA, 2006).

Neste estudo desenvolveu-se um filme ativo biodegradável à base de amido incorporado ao óleo essencial (OE) de cravo-da-Índia e avaliou-se a eficácia de seu uso na qualidade e conservação pós-colheita de tomate cereja orgânico, armazenado em temperatura ambiente

\section{MATERIAL E MÉTODOS}

\section{Material}

Os tomates utilizados no experimento foram adquiridos de produtores orgânicos certificados da cidade de Caetité, Bahia (14,05 S; 42,47 W), transportados em caixas plásticas próprias, previamente higienizadas e, em seguida, encaminhados ao laboratório de Bromatologia do Instituto Federal de Educação, Ciência e Tecnologia da Bahia, Campus Guanambi.

O óleo essencial de cravo-da-Índia, amido de milho, amido modificado, gelatina e glicerol foram adquiridos no comércio local da cidade de Guanambi, Bahia, Brasil. E os reagentes utilizados nas análises físico-químicas foram os próprios para análises (p.a).

\section{Métodos}

\section{Revestimento dos Frutos}

Primeiramente, os tomates cereja orgânicos foram enxaguados em água corrente para retirar a sujeira maior. Em seguida, os frutos foram imersos em solução com hipoclorito de sódio 
200 ppm, por 15 minutos. Após esse período, foram enxaguados com solução de hipoclorito de sódio $40 \mathrm{ppm}$ e os frutos foram secos em condições ambientais. O delineamento experimental para a realização dos revestimentos foi inteiramente casualizado com duas repetições. Os tratamentos foram organizados em esquema fatorial 5 x 5, com cinco concentrações de óleo essencial $(0,0 \%, 2,5 \%, 5,0 \%, 7,5 \%, 10,0 \%)$ e cinco tempos (armazenados por 12 dias - 0, 3, 6, 9 e 12).

Para o preparo da solução filmogênica foram utilizados amido de milho, amido modificado, gelatina e glicerol. As concentrações dos componentes foram 3,0\% de amido, 3,0\% de amido modificado, 3,0\% de gelatina e 3,0\% de glicerol. Todos os ingredientes foram aquecidos em água destilada a $95^{\circ} \mathrm{C}$, por aproximadamente 15 minutos até a obtenção de uma solução gelatinosa. Posteriormente, foram adicionadas diferentes concentrações de óleo essencial de cravo, resultando em cinco tratamentos (T1, T2, T3, T4, T5). Sendo o T1, o tratamento controle, ou seja, o filme sem a adição de OE. Nos demais tratamentos, os filmes foram produzidos com todos os ingredientes supracitados e a adição de óleo essencial de cravo nas concentrações de $2,5 \%, 5,0 \%, 7,5 \%$ e $10,0 \%$.

\section{Análises físico-químicas e microbiológicas}

As análises microbiológicas e físico-químicas foram realizadas nos tomates cereja orgânicos embalados com o filme a cada três dias ao longo dos 12 dias de experimento. As variáveis físico-químicas avaliadas foram: sólidos solúveis (SS), pH, acidez titulável e perda de massa (IAL, 2008).

O teor de sólidos solúveis (SS) foi determinado por leitura direta em refratômetro digital modelo RTD-45, expresso em ${ }^{\circ}$ Brix, com o valor obtido corrigido para $20^{\circ} \mathrm{C}$. O pH foi determinado por meio de um potenciômetro digital previamente calibrado com soluções padrão de $\mathrm{pH}$ 7,0 e 4,0 em 5,0 g de amostras de polpa de tomate homogeneizadas, maceradas e diluídas em 50,0 mL de água destilada. A acidez (AT) foi determinada por titulação com solução de $\mathrm{NaOH}$ $0,1 \mathrm{M}$ e indicador fenolftaleína a 1,0\%, expressa em porcentagem de ácido cítrico em 5,0 g de polpa. A perda de massa fresca foi obtida pela diferença entre a massa inicial dos frutos e os valores obtidos em cada avaliação pesando os frutos em uma balança analítica com precisão de $\pm 0,01 \mathrm{~g}$ (IAL, 2008).

Para as análises microbiológicas, foram realizadas contagens em (UFC/g) em placas para fungos filamentosos, número mais provável por g (NMP/g) de coliformes totais e coliformes termotolerantes, seguindo a metodologia de Silva e colaboradores (2007). Os resultados foram 
submetidos à ANOVA seguida, se necessário, pelo teste pos hoc de Tukey ou análise de regressão, utilizando-se $95,0 \%$ de nível de confiança $(\mathrm{p} \leq 0,05)$.

\section{RESULTADOS E DISCUSSÃO}

A Tabela 1 mostra os resultados obtidos a partir dos valores médios dos parâmetros físicoquímicas dos tomates cereja orgânicos embalados com filme biodegradável adicionados de diferentes concentrações de óleo essencial de cravo e armazenados em temperatura ambiente por 12 dias.

Tabela 1: Valores médios dos parâmetros físico-químicos das amostras de tomate cereja orgânico embalado com filme ativo biodegradável adicionados de diferentes concentrações de óleo essencial de cravo e armazenados em temperatura ambiente por 12 dias. Instituto Federal Baiano, Campus Guanambi, Bahia, Brasil, 2021.

\begin{tabular}{llllll}
\hline Parâmetros & \multicolumn{5}{c}{ Tratamentos } \\
\cline { 2 - 6 } & T1 & T2 & T3 & T4 & T5 \\
\hline Perda de massa (\%) & $37,8^{\mathrm{a}}$ & $25,52^{\mathrm{b}}$ & $32,4^{\mathrm{c}}$ & $28,40^{\mathrm{d}}$ & $19,30^{\mathrm{e}}$ \\
$\mathrm{pH}$ & $3,59^{\mathrm{a}}$ & $3,45^{\mathrm{ab}}$ & $3,23^{\mathrm{c}}$ & $3,46^{\mathrm{ab}}$ & $3,32^{\mathrm{bc}}$ \\
Acidez titulável (\%) & $1,92^{\mathrm{a}}$ & $2,21^{\mathrm{a}}$ & $1,95^{\mathrm{a}}$ & $1,87^{\mathrm{a}}$ & $2,23^{\mathrm{a}}$ \\
Sólidos solúveis (\%) & $5,89^{\mathrm{a}}$ & $5,44^{\mathrm{a}}$ & $5,23^{\mathrm{a}}$ & $5,40^{\mathrm{a}}$ & $5,20^{\mathrm{a}}$
\end{tabular}

*Valores expressos como média \pm desvio-padrão amostral. T1: Tratamento controle; T2: Filme adicionado de 2,5\% OE; T3: Filme adicionado 5,0\% OE; T4: Filme adicionado 7,5\% OE; T5: Filme adicionado 10,0\% OE. Os valores médios com letras diferentes na mesma linha diferem estatisticamente entre si, (Teste de Tukey, $\mathrm{p} \leq 0,05)$.

Fonte: Costa et al., 2022.

Segundo Siqueira (2012), a perda de massa é caracterizada como a perda de água que ocorre no fruto devido ao processo de transpiração, devido à diferença de umidade entre o fruto e a atmosfera externa. $\mathrm{O}$ autor conclui ainda que a utilização de revestimentos comestíveis visa formar uma atmosfera saturada entre a casca e a superfície do fruto, de modo a reduzir a sua transpiração. No entanto, o carácter hidrofílico das soluções filmogênicas à base de polissacarídeos faz com que os frutos possuam uma barreira eficiente contra a saída do vapor de água do interior do fruto.

Os valores médios de perda de massa de todas as amostras diferiram estatisticamente entre si, com menor perda de massa à medida que se aumentou o teor de óleo essencial adicionado ao filme. Os valores de perda de massa variaram entre 19,30 (T5) e 37,8 (T1). As amostras do 
tratamento controle (T1) apresentaram maior média de perda de peso, o que era esperado, pois os frutos foram cobertos com o filme sem a adição do OE (Tabela 1).

O T5, onde os frutos foram embalados com o filme adicionado de 10,0\% de OE, apresentou a menor perda de peso (19,3\%), e que melhor prolongou o tempo de maturação dos tomates cereja orgânicos. Isso pode ser explicado pela presença de uma maior concentração do $\mathrm{OE}$, que pode ter dificultado os processos respiratórios dos frutos, reduzindo assim a velocidade do seu metabolismo.

Segundo Ferreira, Molina e Pelissari (2020), os processos metabólicos se intensificam à medida que o fruto entra em estado de senescência e, como consequência, ocorre a conversão de açúcares em ácidos, promovendo um aumento do $\mathrm{pH}$.

Os valores médios de pH ficaram entre 3,23 (T3) e 3,45 (T2). Pelo teste de Tukey observou-se que houve diferença significativa $(\mathrm{p}<0,05)$ entre os tratamentos. O menor valor foi o observado para o T3, que indica uma menor senescência do fruto com a concentração de $\mathrm{OE}$ em $5,0 \%$.

De acordo com Chitarra e Chitarra (2005), as mudanças na concentração de ácidos orgânicos durante o período de desenvolvimento do fruto diferem de acordo com a espécie. Em alguns casos leva a um aumento, e em outros, à uma diminuição, com o avanço da maturação.

Silva (2016) observou a redução do pH durante os dias de armazenamento, iniciando em 5,54 e terminando aos doze dias com 5,22, quando avaliou a aplicação de revestimento biodegradável produzido a partir de amido de inhame e mucilagem de chia adicionado de OE de laranja doce em mamão minimamente processado.

De acordo com Amancio (2020), a acidez titulável é caracterizada como ácidos livres que estão presentes nos tecidos de frutas e hortaliças, e com a maturação dos frutos há redução da acidez.

As médias finais do teor de acidez dos frutos revestidos com filme com diferentes concentrações de OE de cravo-da-Índia não apresentaram diferenças significativas entre eles (p > $0,05)$ (Tabela 1).

Analisando o comportamento da quantificação da acidez titulável, foi possível observar que o tratamento $\mathrm{T} 5$ (filme adicionado com 10,0\% de OE) apresentou a maior média, indicando que houve menor amadurecimento dos frutos estudados (Tabela 1). O tratamento T4 (filme adicionado com 7,5\% de $\mathrm{OE}$ ), obteve o menor valor, indicando que houve maior amadurecimento do tomate cereja orgânico neste tratamento. 
Com o avanço do amadurecimento dos frutos, esse parâmetro é reduzido. Segundo Chitarra e Chitarra (2005), a acidez do fruto diminui com a aceleração do amadurecimento devido à redução do processo respiratório, com consequente aumento do $\mathrm{pH}$.

A análise de sólidos solúveis indica a quantidade de sólidos que estão dissolvidos no suco ou na polpa da fruta, e há uma tendência de aumento com o avanço da maturação (CHITARRA; CHITARRA, 2005).

Os resultados para o parâmetro de sólidos solúveis apresentados na Tabela 1, ficaram entre 5,20 e 5,89 e não apresentaram diferenças significativas entre eles ( $\mathrm{p} \leq 0,05)$, para todos os tratamentos avaliados. De acordo com o trabalho de Chitarra e Chitarra (2005), os sólidos solúveis consistem principalmente em carboidratos e os valores nos frutos estão na faixa de variação entre 2,0 e $25 \%$. Os valores encontrados neste trabalho estão dentro dessa faixa.

O tratamento T5, com filme adicionado de 10,0\% de OE de cravo, apresentou o menor valor durante os 12 dias de armazenamento, indicando um amadurecimento mais tardio, consequentemente, com melhor conservação dos frutos. Em discordância com este estudo, Damasceno e colaboradores (2003) observaram diferenças significativas entre as médias no parâmetro $\mathrm{pH}$, quando estudaram o efeito da aplicação de filme de fécula de mandioca na conservação pós-colheita de tomate.

Observa-se que com o amadurecimento do fruto há um acúmulo de açúcares, ocasionando um aumento no teor de sólidos solúveis. Corroborando com a pesquisa de Medeiros e colaboradores (2012), esse aumento é normal devido à degradação dos polissacarídeos e à perda de água, resultando na concentração desses sólidos. Em conclusão dos resultados descritos na Tabela 1, verificou-se que para os parâmetros sólidos solúveis e acidez titulável as médias não diferiram estatisticamente, mas houve diferença estatística para as médias dos parâmetros perda de massa e $\mathrm{pH}$.

As Figuras 1 e 2 mostram os gráficos de regressão para os parâmetros de perda de massa e pH, parâmetros analisados para tomate cereja orgânico embalado com filme biodegradável adicionado de diferentes concentrações de óleo essencial de cravo.

Figura 1. Gráfico de regressão do parâmetro de perda de massa em tomate cereja orgânico embalado com filme biodegradável adicionado de diferentes concentrações de óleo essencial de cravo. 


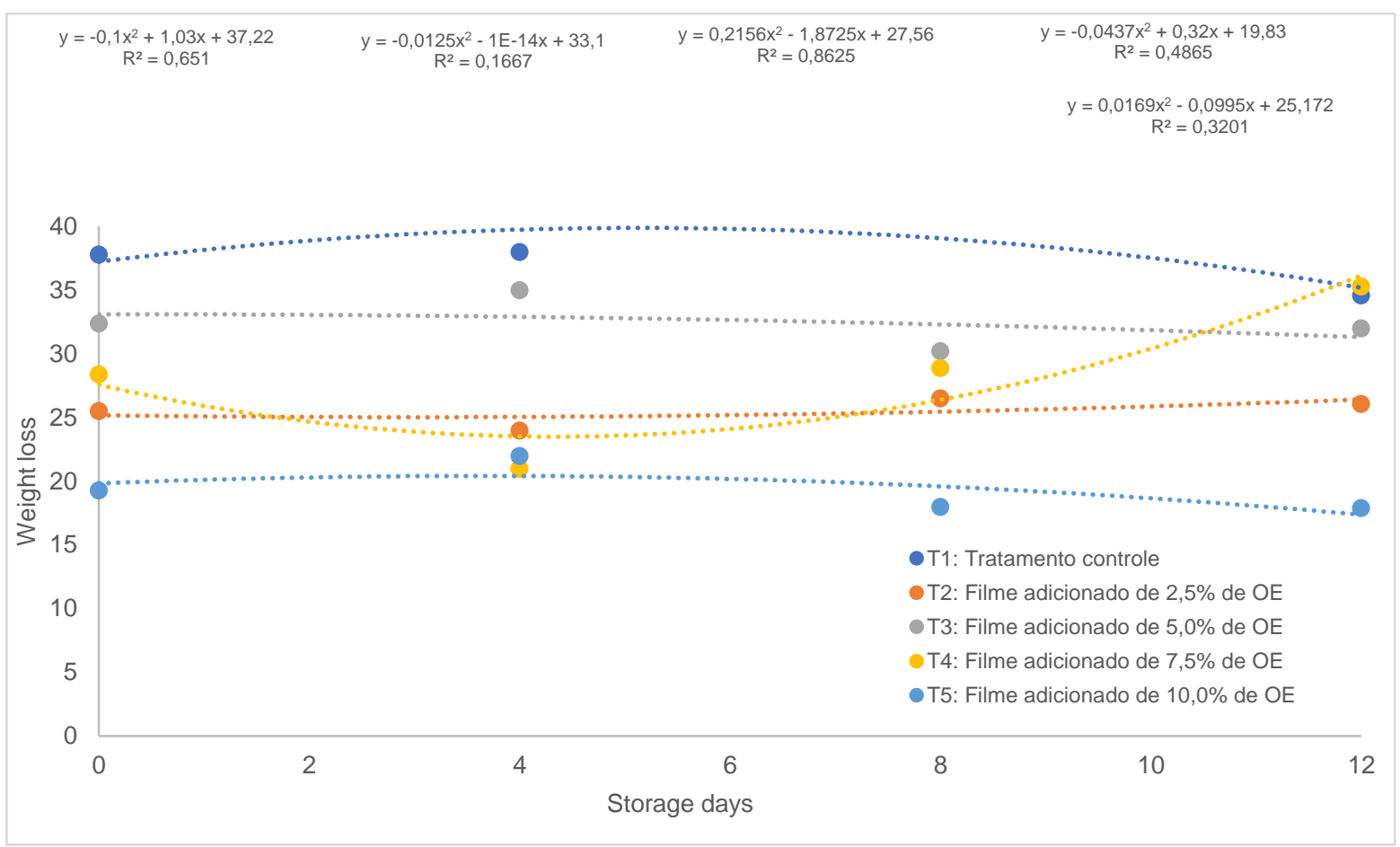

Fonte: Costa et al., 2022.

Ao analisar a Figura 1, é possível observar que o percentual de perda de massa dos frutos diminuiu com 12 dias de armazenamento, com exceção do tratamento T4. Os melhores resultados foram obtidos para os tratamentos T2, T3 e T5, onde os frutos foram embalados com filme adicionado de 2,5, 5,0 e 10,0\% de óleo essencial de cravo, respectivamente, pois os gráficos para estes tratamentos apresentam comportamento próximo ao linear.

Figura 2. Gráfico de regressão do parâmetro de pH de tomate cereja orgânico embalado com filme biodegradável e adicionado de diferentes concentrações de óleo essencial de cravo. 


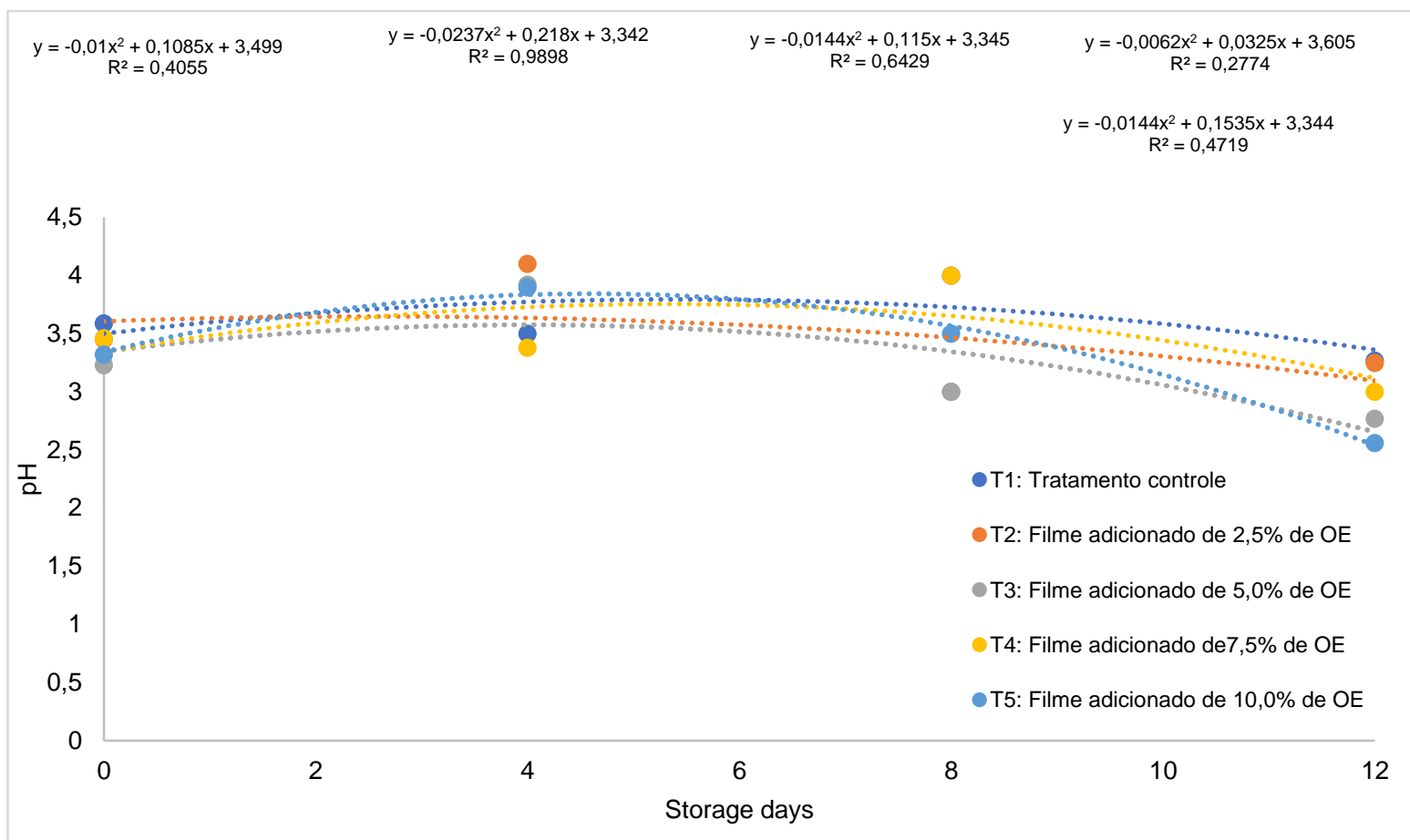

Fonte: Costa et al., 2022.

Os dados da Figura 2 mostra que os resultados apresentaram um comportamento exponencial decrescente a partir do segundo dia de armazenamento (Figura 2).

Observa-se que para todos os tratamentos o $\mathrm{pH}$ final foi muito próximo ao inicial.

Os dados da Tabela 2 mostra os resultados obtidos para a determinação de coliformes totais em frutos de tomate cereja orgânico embalados com filme biodegradável e adicionados em quatro diferentes concentrações de OE de cravo-da-Índia e armazenados em temperatura ambiente por 12 dias. A legislação brasileira não recomenda limites de tolerância para coliformes totais para hortaliças. As análises de coliformes totais são realizadas para avaliar as condições higiênicosanitárias do produto. Já as análises de coliformes termotolerantes são utilizadas para avaliar a contaminação fecal (JAY, 2005).

Tabela 2. Valores médios da contagem de coliformes totais (NMP/g) em tomate cereja orgânico embalado com filme ativo biodegradável adicionado de diferentes concentrações de óleo essencial de cravo-da-Índia e armazenados em temperatura ambiente por 12 dias. Instituto Federal Baiano, Campus Guanambi, 2021.

\section{Coliformes total (NMP/g)}

\begin{tabular}{lllll}
\hline Tratamentos & Tempo 0 & Tempo 4 & Tempo 8 & Tempo 12 \\
\hline T1 & $1,8 \times 10^{2}$ & $2,3 \times 10^{2}$ & $5,6 \times 10^{2}$ & $8,6 \times 10^{2}$ \\
T2 & Sem contagem & $3,3 \times 10^{1}$ & $4,6 \times 10^{2}$ & $3,5 \times 10^{1}$ \\
\hline
\end{tabular}




\begin{tabular}{lllll}
\hline T3 & Sem contagem & $1,6 \times 10^{2}$ & Sem contagem & $1,2 \times 10^{1}$ \\
T4 & $5,0 \times 10^{2}$ & $4,5 \times 10^{2}$ & $5,1 \times 10^{1}$ & $5,6 \times 10^{2}$ \\
T5 & Sem contagem & $3,8 \times 10^{2}$ & $4,8 \times 10^{2}$ & $4,5 \times 10^{2}$ \\
\hline
\end{tabular}

T1: Tratamento controle; T2: Filme adicionado de 2,5\% OE; T3: Filme adicionado 5,0\% OE; T4: Filme adicionado 7,5\% OE; T5: Filme adicionado 10,0\% OE. As médias com letras diferentes na mesma linha diferem estatisticamente entre si, sendo 5,0\% de significância $(\mathrm{P}<0,05)$.

Fonte: Costa et al., 2022.

O tratamento controle (T1) e o tratamento T4 apresentaram contagens de coliformes totais em todos os dias de armazenamento (Tabela 2). Os tratamentos T2 e T3 (filme adicionado com $2,5 \%$ e $5,0 \%$ de $\mathrm{OE}$, respectivamente) foram os mais eficazes em inibir o crescimento de coliformes totais, pois não obtiveram contagens no $1^{\circ}$ dia, mostrando assim a eficácia da sanitização e as baixas contagens no $12^{\circ}$ dia de armazenamento. O tratamento T3 (filme adicionado com 5,0\% de $\mathrm{OE}$ ) apresentou a maior eficiência na inibição desse microrganismo, pois não obteve contagens no $1^{\circ}$ e $8^{\circ}$ dia de armazenamento e com contagens muito baixas no $12^{\circ}$ dia.

Oliveira Filho (2015) relata que a ação dos óleos essenciais como antimicrobianos caracteriza-se pela interação desse produto natural e seus constituintes com a membrana celular dos microrganismos, podendo levar à lise da membrana devido à alteração da permeabilidade.

$\mathrm{O}$ aumento na contagem para o tratamento $\mathrm{T} 4$ pode estar relacionado a danos ao tecido do fruto devido às maiores concentrações de antimicrobiano adicionadas neste tratamento, abrindo caminho para contaminação.

Para coliformes termotolerantes, a Tabela 3 mostra os resultados obtidos em frutos de tomate cereja orgânicos embalados com filme biodegradável e adicionados com diferentes concentrações de óleo essencial de cravo em quatro períodos consecutivos de análise nos 12 dias de avaliação.

Tabela 3. Resultados das médias de análise microbiológica para coliformes termotolerantes (MPN/g) em tomate cereja orgânico embalado com filme ativo biodegradável adicionado de diferentes concentrações de óleo essencial de cravo e armazenado em temperatura ambiente por 12 dias. Instituto Federal Baiano, Campus Guanambi, 2021.

\section{Coliformes termotolerantes (NMP/g)}

\begin{tabular}{lllll}
\hline Tratamentos & Tempo 0 & Tempo 4 & Tempo 8 & Tempo 12 \\
\hline T1 & Presente & Presente & Presente & Presente \\
T2 & Presente & Ausente & Presente & Presente
\end{tabular}


T3

T4

T5
Presente

Ausente

Presente

Presente

Presente

Ausente

Ausente

Ausente

Presente

T1: Tratamento controle; T2: Filme adicionado de 2,5\% OE; T3: Filme adicionado 5,0\% OE; T4: Filme adicionado 7,5\% OE; T5: Filme adicionado 10,0\% OE. As médias com letras diferentes na mesma linha diferem estatisticamente entre si, sendo 5,0\% de significância $(\mathrm{P}<0,05)$.

Fonte: Costa et al., 2022.

Os coliformes termotolerantes constituem um grupo de bactérias que indicam poluição sanitária, pois são restritos ao trato intestinal e presentes em grande densidade nas fezes de animais de sangue quente (CETESB, 2014).

Os resultados obtidos neste trabalho mostram que para os frutos do tratamento T1 houve a presença desses microrganismos em todos os momentos analisados, resultado esperado já que o filme não foi adicionado de OE.

Para os tratamentos de T3 e T5 nos tempos de 8 e 12 dias de análise, houve um controle efetivo do crescimento de coliformes termotolerantes, de acordo com a legislação vigente e adequado para consumo seguro, indicando que o antimicrobiano foi eficiente no controle desse microrganismo.

Moreira (2018), ao estudar a conservação de pinhão minimamente processado com aplicação de revestimento biodegradável com adição de OE de cravo, não identificou a presença de coliformes termotolerantes nas amostras analisadas.

A Tabela 4 mostra os resultados obtidos para a determinação de fungos filamentosos em tomate cereja orgânico embalado com filme biodegradável e adicionado de diferentes concentrações de $\mathrm{OE}$ de cravo em quatro períodos consecutivos de análise nos 12 dias de avaliação.

Tabela 4: Resultados das médias das análises microbiológicas para fungos filamentosos (UFC/g), em tomate cereja orgânico embalado com filme ativo biodegradável adicionado de diferentes concentrações de óleo essencial de cravo e armazenado em temperatura ambiente por 12 dias. Instituto Federal Baiano, Campus Guanambi, 2021.

\section{Fungos filamentosos (UFC/g)}

\begin{tabular}{lllll}
\hline Tratamentos & Tempo 0 & Tempo 4 & Tempo 8 & Tempo 12 \\
\hline T1 & $2,0 \times 10^{1}$ & $3,0 \times 10^{2}$ & $3,0 \times 10^{1}$ & $1,0 \times 10^{1}$ \\
\hline
\end{tabular}




\begin{tabular}{lllll}
\hline T2 & $3,4 \times 10^{1}$ & Sem contagem & $3,0 \times 10^{1}$ & $2,0 \times 10^{1}$ \\
T3 & $2,0 \times 10^{1}$ & Sem contagem & Sem contagem & Sem contagem \\
T4 & $2,0 \times 10^{2}$ & $1,0 \times 10^{2}$ & Sem contagem & Sem contagem \\
T5 & $1,6 \times 10^{2}$ & Sem contagem & $1,0 \times 10^{1}$ & Sem contagem \\
\hline
\end{tabular}

T1: Tratamento controle; T2: Filme adicionado de 2,5\% OE; T3: Filme adicionado 5,0\% OE; T4: Filme adicionado 7,5\% OE; T5: Filme adicionado 10,0\% OE. As médias com letras diferentes na mesma linha diferem estatisticamente entre si, sendo 5,0\% de significância $(\mathrm{P}<0,05)$.

Fonte: Costa et al., 2022.

Ao analisar a Tabela 4, é possível observar que em 12 dias de avaliação, as amostras T3, T4 e T5 não apresentaram contagens para fungos filamentosos, demonstrando assim a eficiência do antimicrobiano. Todas as amostras do tratamento T1 (controle) apresentaram contagens em até 12 dias de armazenamento, pois os frutos não foram embalados com filme adicionado de antimicrobiano.

\section{CONCLUSÃO}

A embalagem com filme biodegradável adicionado de óleo essencial de cravo mostrouse eficiente em prolongar a senescência dos frutos, pois atuou como barreira contra a perda de água pelo tomate cereja orgânico e, além disso, atuou no controle do crescimento de microrganismos totais, coliformes, coliformes termotolerantes e fungos filamentosos.

O tratamento T3, que foi o filme adicionado de 5,0\% de OE de cravo, foi o que, além de controlar o crescimento de microrganismos, melhorou as características físicas e químicas do produto.

\section{REFERÊNCIAS}

AMANCIO, D. F. Efeito da aplicação de coberturas comestíveis na conservação de tomates italianos (Solanum lycopersicum L.)'Ravena'in natura. 2020. $69 \mathrm{f}$. Dissertação (Mestrado em Ciência e Tecnologia de Alimentos) - Universidade Federal Rural do Rio de Janeiro, Seropédica, 2020.

ARRUDA, M.; CARVALHO, L. A.; NETO, J.; JACOMINO, A.; MELO, P. C. Caracterização físico-química de híbridos de tomateiro de crescimento indeterminado em função do espaçamento e número de ramos por planta. Revista Brasileira de Agrociência, Pelotas, v. 11, n. 3, p. 295-298, 2005. 
BAKKALI, F.; AVERBECK, S.; AVERBECK, D.; IDAOMAR, M. Efeitos biológicos dos óleos essenciais. Food and Chemical Toxicology, v. 46, n. 2, p. 446-475, 2008.

CARVALHO, J. R.; PAGLIUCA, L. G. Tomate, um mercado que não para de crescer globalmente. Revista Hortifruti Brasil, Piracicaba, v. 58, n.6, p. 0-40, 2007.

CETESB - Empresa Ambiental do Estado de São Paulo. Relatório de qualidade das praias litorâneas do Estado de São Paulo. São Paulo. SP, 2014.

CHITARRA, M. I. F.; CHITARRA, A. B. Pós-colheita de frutas e hortaliças: fisiologia e manejo. 2.ed. edição, revisão estendida. Lavras: Universidade Federal de Lavras, p. 01-783, 2005.

CHIUMARELLI, M.; FERREIRA, M. D. Qualidade pós-colheita de tomates "Débora" utilizando diferentes coberturas comestíveis e temperaturas de armazenamento.

Horticultura Brasileira, v. 24, p. 381-385, 2006.

CISNERO-ZEVALLOS, L.; KROCHTA, J. M. Atmosfera modificada interna de frutas e vegetais frescos revestidos: Entendendo os efeitos da umidade relativa. Journal of Food Science, v. 67, n. 8, p. 2792-2797, 2002.

DAMASCENO, S.; OLIVEIRA, P. V. S.; TARDE, E.; MACEDO JR, E. K.; LOPES, M. C.; VICENTINI, N. M. Efeito da aplicação de filme de fécula de mandioca na conservação pós-colheita de tomate. Ciência e Tecnologia de Alimentos, Campinas, v.23, n.3, 2003.

FAOSTAT - FOOD AND AGRICULTURE ORGANIZATION OF THE UNITED NATIONS STATISTICS. Disponível em: http://faostat.fao.org/. Acesso em: 25 de janeiro de 2022.

FERREIRA, D. C.; MOLINA, G.; PELISSARI, F. M. Efeito de Revestimento comestível de amido de mandioca e farinha de babaçu (Orbignya phalerata) na qualidade de frutos do Cerrado brasileiro. Food and Bioprocess Technology, v. 13, p. 172-179, 2020.

IAL - INSTITUTO ADOLFO LUTZ. Normas Analíticas do Instituto Adolfo Lutz. Métodos físico-químicos para análise de alimentos. 4. ed. (1. ed. digital), 2008.

IBGE - INSTITUTO BRASILEIRO DE GEOGRAFIA E ESTATÍSTICA. Diretoria de Pesquisas, Coordenação Agropecuária, Levantamento Sistemático da Produção Agrícola, Rio de Janeiro: IBGE, 2021.

JAY, J. M. Microbiologia de alimentos. 6.ed. Porto Alegre: Artmed, 2005.

JUNQUEIRA, A. H.; PEETZ, M. S.; ONODA, S. M. SweetGrape: um modelo de inovação na gestão da cadeia produtiva e de distribuição de hortaliças, 2011. 19p. Disponível em:

<http://www.espm.br/Publicacoes/CentralDeCases/Documentos/SWEET\%20GRAPE.p df $>$. Acesso em: 22 de setembro de 2021.

MEDEIROS, B. G. D. S.; PINHEIRO, A. C.; CARNEIRO-DA-CUNHA, M. G.; VICENTE, A. A. Desenvolvimento e caracterização de um revestimento nanomulticamada de pectina e quitosana - Avaliação de suas propriedades de barreira a 
gases e aplicação em mangas 'Tommy Atkins'. Revista de Engenharia de Alimentos, v. 110, n.3, p. 457-464, 2012.

MOREIRA, M. K. V. Conservação de pinhões minimamente processados por meio de revestimentos comestíveis com características antimicrobianas. $2018.111 \mathrm{f}$. Dissertação (Mestrado em Nutrição e Alimentação) - Universidade Federal de Pelotas, Pelotas, 2018.

OLIVEIRA FILHO, R. D. Incorporação de óleo essencial de manjericão em filmes biodegradáveis à base de galactomanana e óleo de canola, 2015. Disponível em: http://www.repositorio.ufc.br/handle/riufc/16865. Acesso em: 27 de julho de 2021.

SIQUEIRA, A. P. O. Uso de coberturas comestíveis na conservação pós-colheita de goiaba e maracujá. 2012. 91 f. Dissertação de Mestrado. Universidade Estadual do Norte Fluminense Darcy Ribeiro, 2012.

SILVA, M, C, A. Qualidade e potencial funcional de Mamão 'Golden minimamente processado e recoberto com fécula de inhame, mucilagem de chia e óleo essencial de laranja doce. 2016. 129 f. Dissertação (Mestrado em Ciência e Tecnologia de Alimentos) - Universidade Federal da Paraíba, João Pessoa, Paraíba, 2016.

SILVA, N.; JUNQUEIRA, V. C. A.; SILVEIRA, N. F. A.; TANIWAKI, M. H.; SANTOS, R. F.; GOMES, R. A. R. Manual de métodos para análise microbiológica de alimentos. 3.ed. São Paulo: Livraria Varela, 2007.

TURBIANI, F. R. B. Desenvolvimento e caracterização de filmes ativos de alginato de sódio reticulados com benzoato de cálcio. 2007. Dissertação em Engenharia Química, Faculdade de Engenharia Química, Universidade Estadual de Campinas, Campinas, 2007. 